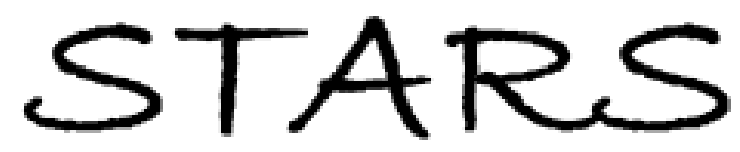

University of Central Florida

STARS

Faculty Bibliography 2010s

Faculty Bibliography

$1-1-2011$

\title{
Polymer-Derived Non-Oxide Ceramic Fibers-Past, Present and Future
}

Sourangsu Sarkar

University of Central Florida

Lei Zhai

University of Central Florida

Find similar works at: https://stars.library.ucf.edu/facultybib2010

University of Central Florida Libraries http://library.ucf.edu

This Review is brought to you for free and open access by the Faculty Bibliography at STARS. It has been accepted for inclusion in Faculty Bibliography 2010 s by an authorized administrator of STARS. For more information, please contact STARS@ucf.edu.

\section{Recommended Citation}

Sarkar, Sourangsu and Zhai, Lei, "Polymer-Derived Non-Oxide Ceramic Fibers-Past, Present and Future" (2011). Faculty Bibliography 2010s. 1853.

https://stars.library.ucf.edu/facultybib2010/1853

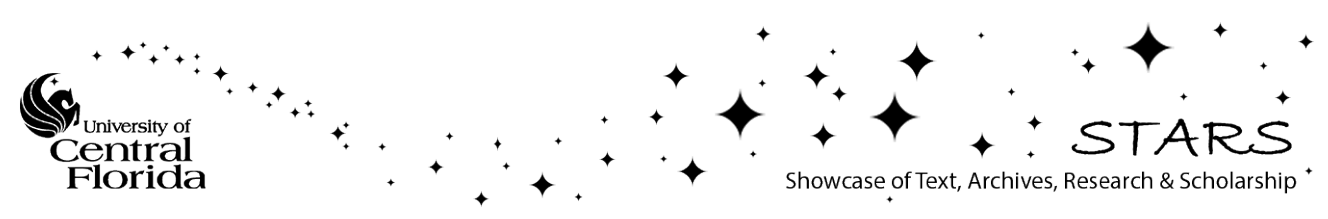




\title{
Polymer-Derived Non-Oxide Ceramic Fibers-Past, Present and Future
}

\author{
Sourangsu Sarkar and Lei Zhai* \\ NanoScience Technology Center and Department of Chemistry, University of Central Florida, \\ 12424 Research Parkway, Orlando, FL 32816, USA
}

Polymer-derived ceramics (PDCs) are a class of multifunctional ceramics synthesized by the thermal decomposition of polymeric precursors. The direct polymer-to-ceramic processing route makes the materials very suitable for the fabrication of complex shaped components and devices through hybrid processing/shaping technologies. Such process has led to significant technology breakthrough in ceramics including the development of ceramic fibers, coatings and thermal stable ceramics. Non-oxide ceramic fibers have been widely used as the skeletal structures in ceramic matrix composites (CMCs) for high temperature applications where the metallic materials suffer serious corrosion and mechanical property deterioration. Fabricating non-oxide ceramic fibers from polymer precursors offers excellent control of the mechanical and chemical properties of the ceramic fibers by manipulating the composition and physical properties of the polymer precursors. A series of high performance ceramic fibers with diameter from nanometers to micrometers have been produced through such polymer-derived ceramic fiber process. Well-designed synthesis of the precursors, materials processing and characterization play the key role in producing ceramic fibers with desired properties. The incorporation of functional materials including carbon nanotubes and polymers into the preceramic polymers can introduce difference functionalities and generate interesting nanosize structures to the ceramic fibers, providing new applications such as catalyzing and energy storage devices. This review highlights the synthesis of polymer precursors and

\footnotetext{
*Author to whom correspondence should be addressed. Email: 1zhai@mail.ucf.edu
}

the development of non-oxide ceramic fibers from different polymer precursors through melt-spinning and electrospinning, presents recent progress in fabricating ceramic fibers with nanosize structures, and discusses the advantage, challenge and future direction of the research in this field.

Keywords: Polymer-Derived, Non-Oxide Ceramic, Fiber, Melt-Spin, Electrospin.

lingenta

\section{CONTENTS}

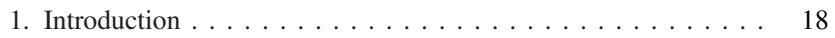

2. Techniques to Produce Preceramic Fibers . . . . . . . . 20

3. Past: The Production of SiC Fibers . . . . . . . . . . 20

4. Present: Multicomponent Ceramic Fibers . . . . . . . . . 21

4.1. Multicomponent Melt-Spun Ceramic Fibers . . . . . . . . 21

4.2. Fabricating Non-Oxide Ceramic Fibers via

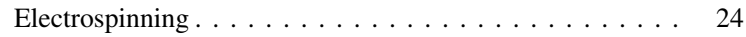

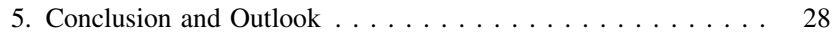

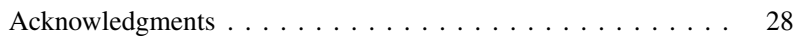

References and Notes . . . . . . . . . . . . . . . . . . . 28

\section{INTRODUCTION}

Non-oxide ceramic fibers have been widely used as the skeletal structures in ceramic matrix composites (CMCs) for high temperature applications where metallic materials suffer serious corrosion and mechanical property deterioration. ${ }^{1}$ The drastic working condition in turbine engines, rocket nozzles and furnaces requires superior mechanical and chemical properties from the ceramic fibers. The elevated operation temperature attributed to the CMCs allows for the improvement of engine efficiency. Producing non-oxide ceramic fibers from their polymer precursors is based on a polymer-derived ceramic (PDC) 
technique. ${ }^{2,3}$ In contrast to the traditional approach to produce ceramics involving powder technology that requires the powder shaping and sintering additives, the direct polymer-to-ceramic processing route of PDCs not only provides the processable materials for the fabrication of ceramics with different structures including fibers, layers, or composites, but also allows the control over the polymer precursor composition which contributes significantly to the final ceramic properties. The molecular structure of the preceramic polymers has significant influence on the ceramic's composition and structures that determine the ceramic properties such as chemical and thermal stability and mechanical properties. Therefore, the synthesis of appropriate preceramic polymers holds the key to the realization of superior ceramic materials. In order to obtain ceramic fiber with desired properties, the structure of the polymer precursors needs to be carefully designed to meet several requirements. The requirement of the preceramic polymers for the fiber fabrication includes:

(1) appropriate rheology to offer non-Newtonian flow of the material and suitable viscosity during the spinning,

(2) reactivity to fuse the fibers for subsequent pyrolysis,

(3) controllable degradation during the pyrolysis to prevent the disruption of the bulk structure and achieve high density fibers with high ceramic yield, and

(4) controlled the formation of nano- or micro-structures.

Polymer composition should be controlled to generate specific ceramic fiber such as $\mathrm{SiC}$ (silicon carbide), $\mathrm{SiCN}$ (silicon carbonitride), or SiBCN (silicon borocarbonitride), ideally, with selected nanostructures after pyrolysis. Suitable rheology in melt state and in solution is necessary for melt spinning and electrospinning. The green polymer (preceramic) fibers must be infusible after post-spun treatment to maintain the fiber integrity upon pyrolysis. The amount of extraneous small groups in polymer precursors should be minimized to increase the ceramic yield and the density, as well as avoid the formation of pores/voids.

Over the past decades, various preceramic polymers with novel properties have been developed, laying the foundation for the generation of ceramic fibers. The fabrication of ceramic fibers through PDCs route includes three steps:

(i) synthesizing/modifying preceramic polymers,

(ii) spinning (melt-spinning or electrospinning), and solidifying polymer fibers, and

(iii) pyrolyzing the polymer fibers into ceramic fibers.

The combined effort from chemists, materials scientists and engineers has generated ceramic fibers with interesting properties. These fibers can maintain the mechanical properties up to $2000{ }^{\circ} \mathrm{C}$, process excellent oxidation and corrosion resistance at high temperature, and have interesting nanosize structures. Such development not only allows the application of ceramic fibers in traditional CMCs but also pave a way to new applications such as energy conversion and storage devices. This review article overviews the development of PDC ceramic fibers with the outlook of future research. In this review, the spinning technology will be first introduced followed by the development of commercialized SiC ceramic fibers. The recent development of multi-component ceramic fibers will cover the synthesis of various preceramic polymers and interesting ceramic fiber structures induced by electrospinning. The future research will be discussed in the conclusion remarks.
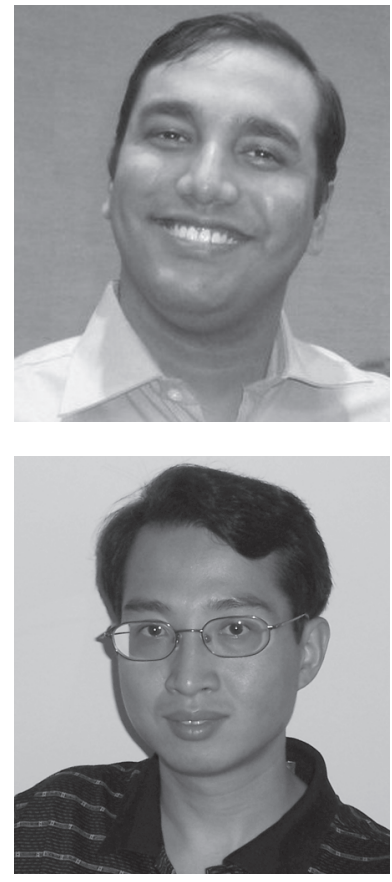

Sourangsu Sarkar obtained his B.S. in chemistry and polymer science and technology from the University of Calcutta. He has worked with Dr. Lei Zhai on polymer-derived ceramics (PDCs) from 2005 to 2010 at the University of Central Florida. His research focused on the fabrication of superhydrophobic PDC fibers, PDC fibers with aligned multiwalled carbon nanotubes and structural investigation of high temperature stable silicon borocarbonitride ceramics. After he obtained his Ph.D. degree in 2010, he joined Dr. SonBinh Nguyen's group at Northwestern University as a postdoctoral fellow working on carbon nanotube/polymer nanocomposites.

Lei Zhai is an associate professor at NanoScience Technology Center and Department of Chemistry at the University of Central Florida. He obtained B.S. degree in chemcial engineering at East China University of Science and Technology and M.S. degree in chemistry from East Tennessee State University. He received the Ph.D. degree from Carnegie Mellon University and worked as a postdoctroal research associate at Massachusetts Institute of Technology before he joined UCF in 2005. His research interest includes polymer derived ceramics, surface engineering, synthesis and self-assembly of conductive polymers, and composite materials for energy conversion and stroage. He has published more than 50 peer reviewed papers. He is the recepient of NSF CAREER award and serves as an associate editor for Materials Express. 


\section{TECHNIQUES TO PRODUCE PRECERAMIC FIBERS}

Green polymer fibers (or preceramic fibers) are fabricated through either a melt-spinning or an electrospinning process. Melt-spinning is a traditional technique to manufacture polymer fibers without the use of flammable solvents, where the melt polymer is pumped through a spinnert with lots of small holes. Appropriate viscosity is required for the melt polymers to be spinnable. The soft polymer fibers cool down and solidify after passing through the holes, and are collected on a take-up wheel (Fig. 1(a)). The size of the polymer fibers, ranging from several micrometers to tens of micrometers, is controlled by the spinnert hole diameter and shear rates. The polymer structures can be altered by stretching extruded polymer fibers when solidifying. Such process orients polymer chains along the fiber axis, creating a stronger fiber and leading to more ordered crystalline ceramic structures. Electrospinning, on the other hand, is a simple and versatile technique to generate continuous ultrathin fibers in nanometers and micrometers from various polymeric materials. In a typical design, the electrospinning setup consists of four basic components: a high voltage power supply, a syringe pump, a spinnert, and an electrically conductive collector. For most of the electrospinning purposes, an ordinary hypodermic needle and an aluminum foil or silicon $(\mathrm{Si})$ wafer is used as the spinnert and collector electrode respectively. The polymer solution is fed into a plastic syringe connected to the metallic needle. The syringe pump is used to control the flow rate of the polymer solution during electrospinning. The basic working principle is primarily based on electrostatic interactions. When a high electrical voltage is applied between the spinnert and the collector plate, the pendent droplet becomes highly charged and takes the shape of a conelike meniscus, often referred to as Taylor cone, as a result of electrostatic repulsions between the surface charges and also the electrostatic attractions from the oppositely charged collector electrode, which is grounded. When the voltage or the electrical field strength surpasses a critical or threshold value to overcome the surface tension, a jet
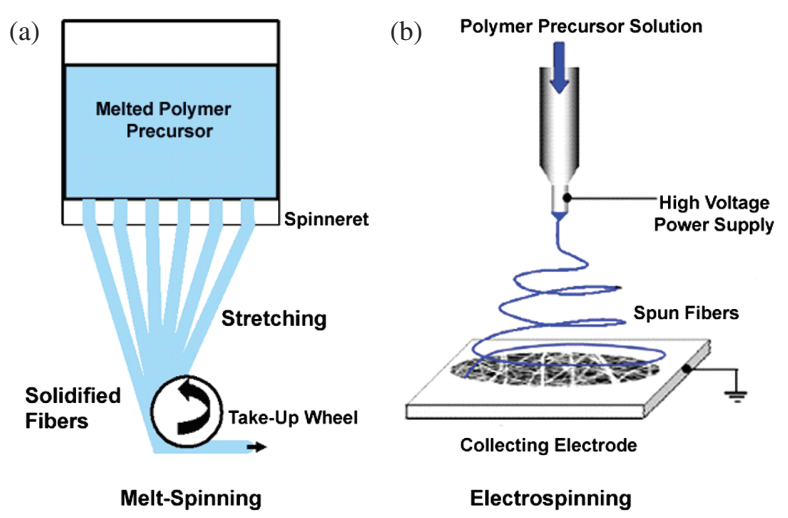

Fig. 1. Illustration of melt-spinning and electrospinning process. is emitted and moves towards the collector electrode. The electrified jet then continuously experiences a rapid bending and whipping process in which the jet is continuously stretched and elongated by the electrostatic forces, the solvent evaporates, leading to the formation of non-woven fabric mat on the collecting electrode. ${ }^{4-9}$ Orientation can be achieved by using a rotating take-up wheel, aligned collecting electrodes or a deflection voltage (Fig. 1(b)). ${ }^{8}$ Electrospinning requires that polymers have good solubility in solvents with decent spinnability. It provides good control over the fiber size and morphology by tuning the polymer solution properties (i.e., polymer concentration and the choice of solvents) and operating parameters (i.e., voltage, solution feeding rate and electrode distance).

\section{PAST: THE PRODUCTION OF SIC FIBERS}

The objective of fabricating non-oxide ceramic fibers is to replace carbon fibers in CMCs for high temperature applications. Although being widely used in composite reinforcement, carbon fibers suffer from a low oxidation onset temperature around $450{ }^{\circ} \mathrm{C}$ in air, which limits their application at high temperatures in an oxidative environment. ${ }^{10}$ Therefore, the target ceramic fibers are required to maintain good mechanical properties and oxidation resistance at high temperature which called for the research in PDC fibers.

$\mathrm{SiC}$ (silicon carbide) based ceramic fibers were first reported by Yajima, ${ }^{11}$ through an alkali metal promoted dehalocoupling of chlorosilanes followed by a Kumada rearrangement (Fig. 2). The resultant polymers, with a molecular weight around $1500 \mathrm{Da}$, were melt-spun into green fibers $(\sim 20 \mu \mathrm{m})$ in $\mathrm{N}_{2}$ gas. The curing of the green fibers were performed by either thermal oxidation in air at temperature of $100-200{ }^{\circ} \mathrm{C}$ or by electron beam irradiation in $\mathrm{He}$ gas followed by a thermal treatment in an inert gas. In thermal oxidation, green fibers became

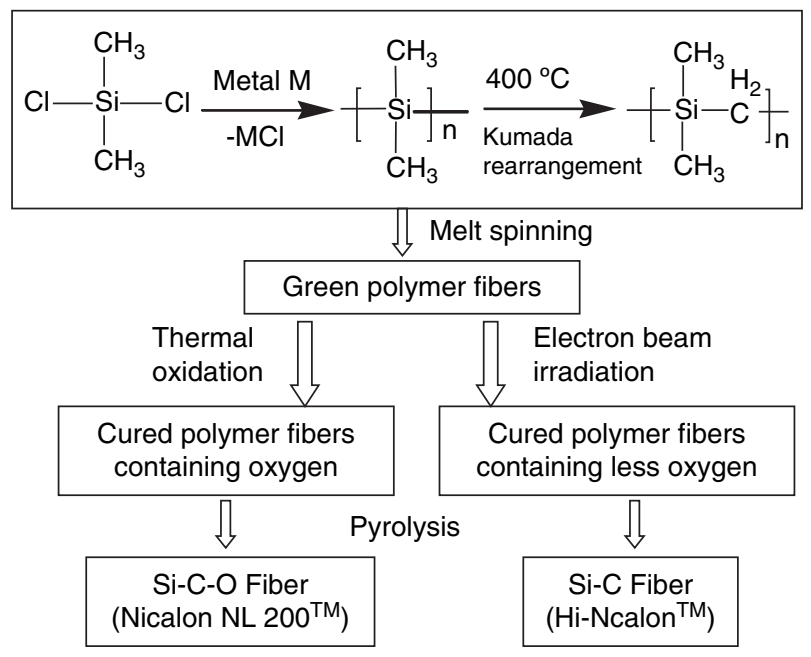

Fig. 2. Fabrication scheme of $\mathrm{SiCO}$ and $\mathrm{SiC}$ ceramic fibers. 
infusible by the cross-linkage via $\mathrm{Si}-\mathrm{O}-\mathrm{Si}$ and $\mathrm{Si}-\mathrm{O}-\mathrm{C}$ bonds with $7 \mathrm{wt} \%$ increase of oxygen in the fibers. ${ }^{12-14} \mathrm{In}$ comparison, electron beam crosslinked the $\mathrm{Si}-\mathrm{H},-\mathrm{CH}_{2}-$ or $-\mathrm{CH}_{3}$ groups that introduced less than $1 \%$ oxygen in the fibers. ${ }^{15,16}$ Green fibers cured by both methods were pyrolyzed at $1200^{\circ} \mathrm{C}$ in $\mathrm{Ar}$ or $\mathrm{N}_{2}$, which led to high tensile strength $\mathrm{SiCO}(\sim 10 \mathrm{wt} \%$ oxygen) and $\mathrm{SiC}(<1 \mathrm{wt} \%$ oxygen). The characterization of these ceramic fibers revealed that $\mathrm{SiCO}$ fibers contained $\beta$-SiC nanocrystals, free carbon and an amorphous silicon oxycarbide $\left(\mathrm{SiC}_{x} \mathrm{O}_{y}\right)$, while the microstructures of $\mathrm{SiC}$ fibers is a mixture of $\beta$-SiC crystals with large amount of glassy carbon and a very small amount of $\mathrm{SiC}_{x} \mathrm{O}_{y}$ (Fig. 2). This technology was later used by Nippon Carbon Co., Ltd. (NCK) to produce continuous $\mathrm{SiC}$ based ceramic fibers under the trade name Nicalon NL-200 ${ }^{\mathrm{TM}}$ (thermal treated, $\mathrm{Si}_{0.566} \mathrm{C}_{0.317} \mathrm{O}_{0.117}$ ) and Hi-Nicalon ${ }^{\mathrm{TM}}$ (irradiation treated, $\mathrm{Si}_{0.624} \mathrm{C}_{0.371} \mathrm{O}_{0.0 .005}$ ). The Hi-Nicalon ${ }^{\mathrm{TM}}$ has similar tensile strength $(\sim 3 \mathrm{GPa})$ and tensile modulus $(\sim 270 \mathrm{GPa})$ as Nicalon NL-200 $0^{\mathrm{TM}}$ at room temperature, but demonstrates better stability at high temperature $(1623 \mathrm{~K})$. After a high temperature treatment, the size of $\beta$-SiC crystallite in Hi-Nicalon ${ }^{\mathrm{TM}}$ is smaller than that of $\beta$-SiC crystallite in Nicalon NL-200 ${ }^{\mathrm{TM}}$. The inhibition of the $\beta$-SiC crystal growth is due to the presence of large amount of free carbon in Hi-Nicalon ${ }^{\mathrm{TM}}$. In contrast, Nicalon ${ }^{\mathrm{TM}}$ prepared by oxidation curing loses carbon and oxygen as $\mathrm{CO}$ by a carbothermal reduction. The remaining $\mathrm{SiC}$ material tends to grow into larger crystals at high temperature. ${ }^{17}$ When the $\mathrm{SiC}$ based ceramic fibers are heated above $1200{ }^{\circ} \mathrm{C}$, the grain coarsening and the crystal growth as well as the release of gases cause the loss of structural integrity. ${ }^{18,19}$ In order to improve the thermal stability of Nicalon ${ }^{\mathrm{TM}} \mathrm{SiC}$ fibers, Yajima et al. modified polycarbosliane with titanium alkoxides and pyrolyzed the preceramic fibers at $1700{ }^{\circ} \mathrm{C}$ under nitrogen to produce $\mathrm{Si}-\mathrm{Ti}-\mathrm{C}-\mathrm{O}$ fibers. The fibers contained $\beta$-SiC-type and TiC-type phase and were stable up to $1300{ }^{\circ} \mathrm{C}$ with tensile strength and elastic modulus of 3 and $300 \mathrm{GPa}$ at room temperature, respectively. However, the mechanism of such improvement was not clear and further improvement of the thermal stability remained challenging. ${ }^{20,21}$

\section{PRESENT: MULTICOMPONENT CERAMIC FIBERS}

\subsection{Multicomponent Melt-Spun Ceramic Fibers}

The requirement of improved mechanical and thermal stability of CMCs in 1990's made it necessary to produce ceramic continuous fibers with excellent performance at high temperature. The targeted properties of the ceramic fibers include:

- Fiber diameter: below $15 \mu \mathrm{m}$

- Tensile modulus: above $350 \mathrm{GPa}$
- Tensile strength: above $2.1 \mathrm{GPa}$ (at $25.4 \mathrm{~mm}$ gauge length).

- Tensile strength: above $1.4 \mathrm{GPa}$ (at $1673 \mathrm{~K}$ in Ar and air at $57.4 \mathrm{~mm}$ gauge length).

- Maintenance of tensile strength: above $80 \%$ after holding 12 hours at $1673 \mathrm{~K}$ in air and 12 hours at $1873 \mathrm{~K}$ in $\mathrm{Ar}^{22}$

Multicomponent ceramic fibers including polycarbosilazane-derived $\mathrm{SiCN}$ fibers and $\mathrm{SiBCN}$ fibers were proposed for the improvement of the thermal stability and oxidation resistance of non-oxide ceramic fibers. The design concept for amorphous non-oxide ceramic fibers is to build a structure by the combination of $\mathrm{Si}$ and $\mathrm{B}$ with $\mathrm{N}$ or $\mathrm{C}$ where the diffusion coefficients of $\mathrm{Si}$ or $\mathrm{B}$ in the compounds are extremely low. The strong covalent bonds would show negligible contributions to the enthalpy of formation from long-range bonding interactions that drive crystallization, preventing the grain coarsening and crystal growth. Such amorphous structure could meet the requirements of durability while resisting crystallization. $\mathrm{SiCN}$ fibers that can retain structural integrity up to $1400{ }^{\circ} \mathrm{C}$ have been fabricated from poly(organosilazanes) obtained through ammonolysis or aminolysis reactions with chlorosilanes (Fig. 3(a)), ${ }^{23}$ as well as from commercially available precursors such as Ceraset $^{\mathrm{TM}}$ (PUMVS) (Fig. 3(b)). ${ }^{24}$ Ceraset $^{\mathrm{TM}}$ is an oligosilazane with average molecular weight of 400 . These oligomers are not suitable for melt-spinning due to low viscosity. Further polymerization to increase the molecular weight produces a three-dimensional crosslinked unspinnable product due to

(a)

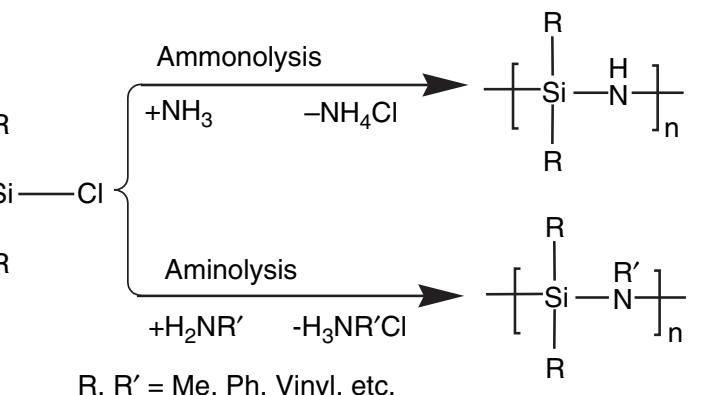

(b)

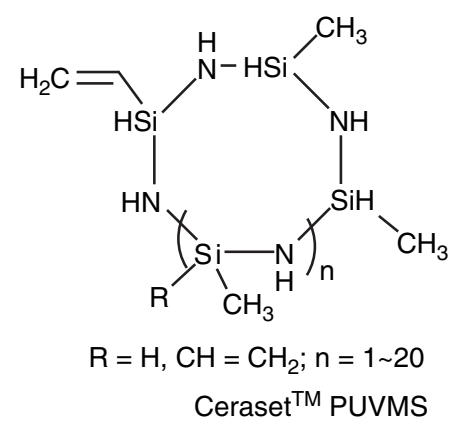

Fig. 3. (a) Fabrication of polycarbosilazane from chlorosilanes, and (b) chemical structure of Ceraset $^{\mathrm{TM}}$. 
the crosslinking of the vinyl groups. Raj and coworkers used zirconium alkoxides to control the polymerization of PUMVS. The procedure produced a viscous spinnable polymer which was melt-spun into $\sim 10-60 \mu \mathrm{m}$ fibers. These fibers were crosslinked at room temperature for overnight (probably through hydrolysis) and pyrolyzed at $1000{ }^{\circ} \mathrm{C}$ to obtain ceramic fibers with the composition $\mathrm{SiZr}_{0.13} \mathrm{C}_{0.46} \mathrm{~N}_{0.785} \mathrm{O}_{0.69}$. The tensile strength (2.2-2.8 GPa) and Young's Modulus (160-190 GPa) of the fibers are comparable with Hi-Nicalon ${ }^{\mathrm{TM}}$ fibers. The systematic investigation of oxidation behavior of $\mathrm{SiCN}$ based and $\mathrm{SiC}$ based ceramic fibers demonstrates that the oxidation rates (parabolic rate) of the $\mathrm{SiCN}$ fibers are lower than those of the $\mathrm{SiC}$ fibers. The oxidation resistance of $\mathrm{Si}$ based ceramic fibers is due to the formation of a thin layer of silicon dioxide $\left(\mathrm{SiO}_{2}\right)$ on the fiber surface that can greatly reduce the oxygen permeability. The dependence of the oxidation rate on the fraction of $\mathrm{Si}-\mathrm{C}$ and $\mathrm{Si}-\mathrm{N}$ bonds in $\mathrm{SiCN}$ systems suggests that the possible formation of silicon oxynitride $(\mathrm{SiON})$ or silicon oxycarbonitride (SiCON) sub-layers further reduces the oxygen permeability. The SiCNZr ceramic fibers from zirconium alkoxide treated Cerase $^{\mathrm{TM}}$ have low parabolic rate due to their low carbon content. ${ }^{25-29}$

Ishikawa and co-workers synthesized SiAlCO fibers using polyaluminocarbosilane prepared by the reaction between polycarbosilance and aluminum acetylacetonate at $300{ }^{\circ} \mathrm{C}$ in a nitrogen atmosphere. Polyaluminocarbosilane was melt spun at $220{ }^{\circ} \mathrm{C}$ and the spun fibers were cured in air at $160{ }^{\circ} \mathrm{C}$. The cured fibers were pyrolyzed at $1300{ }^{\circ} \mathrm{C}$ to produce SiAlCO fibers which were subsequently converted into a sintered $\mathrm{SiC}$ fibers at temperature over $1800{ }^{\circ} \mathrm{C}$. It was found that the content of aluminum in the fibers has to be less than $1 \mathrm{wt} \%$ to obtain a very strong $\mathrm{SiC}$ fiber. The sintered $\mathrm{SiC}$ fiber showed high tensile strength $(>2.5 \mathrm{GPa})$ and tensile modulus $(>300 \mathrm{GPa})$, and could maintain its mechanical strength up to $1900{ }^{\circ} \mathrm{C}$. $80 \%$ of the initial strength was preserved when the fiber was treated at $2000{ }^{\circ} \mathrm{C}$ for 1 hour in Ar. In Comparison, the strength of Hi-Nicalon was reduced to $65 \%$ and $40 \%$ of its initial strength after being treated in Ar for 1 hour at $1550{ }^{\circ} \mathrm{C}$ and $1800{ }^{\circ} \mathrm{C}$, respectively. In addition, the sintered $\mathrm{SiC}$ fiber retained $100 \%$ and $50 \%$ of its initial strength after exposed in air at $1,000{ }^{\circ} \mathrm{C}$ and $1,300{ }^{\circ} \mathrm{C}$ for 100 hours, respectively. In contrast, Hi-Nicalon treated under the same testing condition could maintain $73 \%$ and $23 \%$ of its initial strength, respectively. The test of the sintered $\mathrm{SiC}$ fibers showed excellent heat resistance and oxidation resistance compared to all types of SiC-based continuous fiber. Such thermal stability of the sintered $\mathrm{SiC}$ fiber was believed to be caused by the dense sintered structure composed of nearly stoichiometric $\mathrm{SiC}$. The good oxidation resistance in the presence of alkali element of the fiber was attributed to the small amount of $\mathrm{Al}_{2} \mathrm{O}_{3}$ in the fiber. $^{30}$
Incorporating boron in the $\mathrm{SiBCN}$ ceramic system has been achieved by using various boron containing polymer precursors (i.e., borazine-substituted polysilazane, crosslinked borane/borazine derivatives and borane crosslinked dichlorovinylsilanes) to improve the thermal stability and oxidation resistance. ${ }^{31-41}$ The resulted SiBCN bulk ceramics retain their amorphous structures usually at $1600{ }^{\circ} \mathrm{C}$ and even up to $2200{ }^{\circ} \mathrm{C}$, attributed to the presence of boron in the ceramic to retard the crystallization process. ${ }^{42}$ The oxidation resistance is improved by the formation of a sub-layer of a mixture of SiBCNO glass with $\mathrm{BN}$ precipitates upon the exposure to oxygen at high temperature. ${ }^{43}$

Although the polymer precursors can generate high performance ceramics, their poor solubility and high degree of crosslinking prevents the fabrication of ceramic fibers. The modification of the polymer synthesis route aimed at reducing the degree of crosslinking to make polymer spinnable. Sneddon and coworkers used monofunctional boranes such as pinacolborane (PIN), 1,3-dimethyl-1,3diaza-2-boracyclopentane (BCP) and 2,4-diethylborazine (DEB) to replace multifunctional borazine ${ }^{44}$ in the reaction with hybridopolysilanzane (HPZ, by Dow Corning) to develop melt-spinnable boron-based polymer precursors (Fig. 4). Uniform fibers were fabricated from the melt polymers via melt-spinning. PIN-HPZ polymer green fibers $(\sim 30-40 \mu \mathrm{m})$ were cured with $\mathrm{HSiCl}_{3}$ followed by an exposure to humid air. The subsequent pyrolysis at $1200{ }^{\circ} \mathrm{C}$ in argon produced $\mathrm{SiBCN}$ ceramic fibers that remained amorphous at $1600{ }^{\circ} \mathrm{C}$.

Bernard et al. took another route to fabricate $\mathrm{SiBCN}$ ceramic fibers by using tris(dichloromethylsilylethylborane) developed by Riedel and coworkers to synthesize

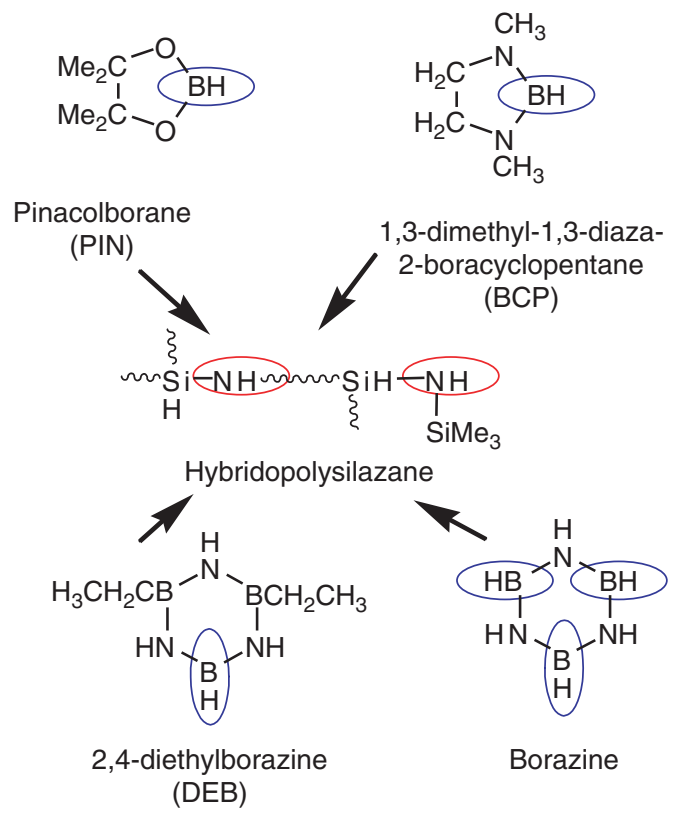

Fig. 4. Monofunctional boranes replaced borazine to react with HPZ for spinnable polymers. 
the preceramic polymer. ${ }^{45}$ In contrast to Riedel's route (Fig. 5(a) $)^{31}$ where ammonia was used, using less reactive methylamine to slow down the crosslinking temperature leads to a meltable polymer with suitable rheology for melt-spinning (Fig. 5(b)). Uniform green fibers with an average diameter of $18 \mu \mathrm{m}$ were obtained from meltspinning. The curing of the green fibers was performed by a slow heating to $200{ }^{\circ} \mathrm{C}$ in an $\mathrm{NH}_{3}$ atmosphere, which crosslinked the polymer backbone. The pyrolysis of the green fibers in nitrogen at $1400{ }^{\circ} \mathrm{C}$ produced 8-10 $\mu \mathrm{m} \mathrm{Si}_{3.0} \mathrm{~B}_{1.0} \mathrm{C}_{5.0} \mathrm{~N}_{2.4}$ ceramic fibers with $1.5 \mathrm{GPa}$ tensile strength at room temperature and $1.3 \mathrm{GPa}$ tensile strength at $1600{ }^{\circ} \mathrm{C}$. The high temperature stability and oxidation resistance of the SiBCN ceramic fibers was investigated in nitrogen and air, respectively. As shown in Figure 6, the glass-like texture of the SiBCN fibers retains at 1500 and $1650{ }^{\circ} \mathrm{C}$, while granular texture appears at $1750{ }^{\circ} \mathrm{C}$ due to an amorphous-to-crystalline transition. The oxidation studies showed only a slight weight increase (2.9\%) during the oxidation treatment from $1100{ }^{\circ} \mathrm{C}$ to $1500{ }^{\circ} \mathrm{C}$, suggesting that the $\mathrm{SiBCN}$ fibers had good oxidation resistance. ${ }^{45}$ High quality $\mathrm{SiBCN}$ ceramic fibers have also been fabricated by the pyrolysis of a preceramic $\mathrm{N}$-methylpolyborosilazane made from trichlorosilylaminodichlorobornae $\left(\mathrm{Cl}_{3} \mathrm{Si}-\mathrm{NH}-\mathrm{BCl}_{2}\right){ }^{46}$ and polysilazane<smiles>C=C[Si](C)(Cl)Cl</smiles><smiles>CCCCCCCCCCC(C)(C)C</smiles><smiles>BB(B)C(C)[Si](C)(Cl)Cl</smiles>
$\mathrm{R}=\mathrm{C}_{2} \mathrm{H}_{4} \mathrm{SiCH}_{3} \mathrm{Cl}_{2}$<smiles>[R]B([R])C(C)[Si](C)(N(C)C)C(C)(C)C</smiles>

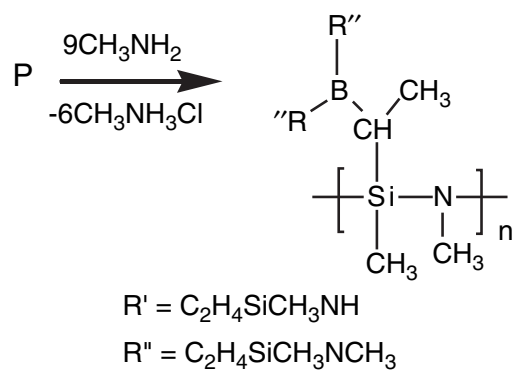

Fig. 5. Synthesis of (a) $\left[\mathrm{B}\left(\mathrm{C}_{2} \mathrm{H}_{4} \mathrm{SiCH}_{3} \mathrm{NH}\right)_{3}\right]_{n}$ (unspinnable polymer) via ammonolysis, and (b) $\left[\mathrm{B}\left(\mathrm{C}_{2} \mathrm{H}_{4} \mathrm{SiCH}_{3} \mathrm{NCH}_{3}\right)_{3}\right]_{n}$ (spinnable polymer) via aminolysis.
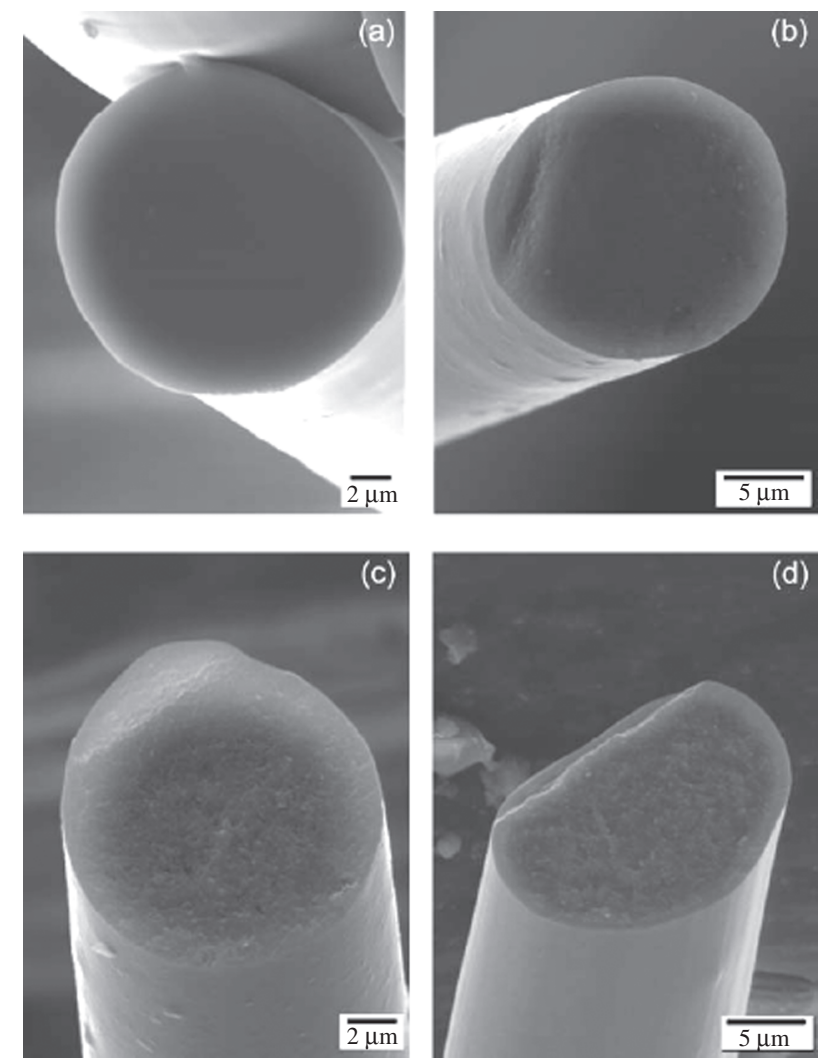

Fig. 6. SEM images of the cross-sections of the $\mathrm{Si}_{3.0} \mathrm{~B}_{1.0} \mathrm{C}_{5.0} \mathrm{~N}_{2 .}$ ceramic fibers annealed at (a) $1500{ }^{\circ} \mathrm{C}$, (b) $1650{ }^{\circ} \mathrm{C}$, (c) $1750{ }^{\circ} \mathrm{C}$, and (d) $1900{ }^{\circ} \mathrm{C}$. Reprinted with permission from [45], S. Bernard et al., J. Chem. Mater. 15, 289 (2005). () 2005, Royal Society of Chemistry.

made from one-step condensation of silane, $\mathrm{BCl}_{3}$ and silazane. ${ }^{47}$

The most advantageous feature of polymer-derived multicomponent ceramic fibers is the incorporation of carbon or boron in silica and silicon nitride, which can not be achieved through conventional solid state reactions or other synthetic approaches. The carbon in silica and silicon nitride has significant impact on the structure and properties of ceramic fibers. As shown in the reported studies, carbon hinders the crystallization of $\mathrm{SiO}_{2}$ and $\mathrm{Si}_{3} \mathrm{~N}_{4}$ up to $1500{ }^{\circ} \mathrm{C}$. Boron-containing $\mathrm{SiCN}$ demonstrates higher thermal stability and crystallizes around $1700{ }^{\circ} \mathrm{C}$. Such behavior grants multicomponent ceramic fibers an amorphous matrix for high-temperature applications free of grain-boundary related properties such as corrosion, grain growth, and creep. In addition, multicomponent ceramic fibers demonstrate excellent tolerance to oxygen which causes severe degradation of polycrystalline ceramics at high-temperature. The difference in the hightemperature behavior between Nicalon and Hi-Nicalon $\mathrm{SiC}$ fibers indicates that eliminating oxygen is crucial to improve the creep resistance and crystallization resistance at high temperatures. In contrast, the nanostructure of amorphous $\mathrm{SiCN}$ with up to several wt\% oxygen is stable at high temperature without losing the resistance 
to crystallization and creep. The current research aims at developing cost effective synthetic route to produce cheap and novel functionalized preceramic polymers and understanding the relationship between the polymer composition and final ceramic properties where monitoring the structural evolution during the pryrolysis plays an important role.

\subsection{Fabricating Non-Oxide Ceramic Fibers via Electrospinning}

All of the SiC, SiCN and SiBCN ceramic fibers discussed above were fabricated through melt-spinning with diameter of several microns. Recently, fabricating non-oxide ceramic fibers through electrospinning has attracted much attention since electrospinning can generate polymer fibers with good control of fiber size and morphology. Similar to melt-spinning, appropriate polymer structures are required to obtain uniform electrospun polymer fibers. Both theoretical and experimental studies clearly indicated that the elasticity and entanglement of polymer chains are crucial in obtaining uniform fibers. ${ }^{48,49}$ Sneddon, Allcock and coworkers pioneered the fabrication of electrospun boron carbide/carbon ceramic nanofibers from a single source polymer precursor, poly(norbornenlyldecaborane) (PND, molecular weight is equal to $32 \mathrm{kDa}){ }^{50}$ The electrospinning of PND in tetrahydrofuran (THF) solutions of different concentrations generated microsize fibers $(20 \%)$, nanosize fibers $(13 \%)$ and nanosize fibers with beads $(10 \%)$. Boron carbide fibers were produced through the pyrolysis of the green fibers at $1000-1300{ }^{\circ} \mathrm{C}$. $\mathrm{SiC}$ fibers were produced by Youngblood et al. through the electrospinning of preceramic poly(carbomethylsilane) (PCmS). Polystyrene (PS) was added to low molecular weight PCmS (3500 Da) solutions to improve the spinnability. The amount of PS was kept low to prevent the void formation in the fibers during the pyrolysis. The electrospun fibers were crosslinked by a UV radiation and pyrolyzed at $1200{ }^{\circ} \mathrm{C}$. This process produced SiC/silica core-shell nanofibers with a $30 \mathrm{~nm}$ thick silica shell. ${ }^{51}$

Recently, Salles et al. reported the fabrication of novel boron nitride $(\mathrm{BN})$ submicron diameter fibers by thermal conversion of electrospun fibers from a blend of polyacrylonitrile (PAN) and poly[(B-(methylamino)borazine] blend solutions. ${ }^{52}$ Twelve-percent PAN was added to the low molecular weight $(900 \mathrm{Da})$ poly[(B(methylamino)borazine] $N, N$-dimethylformamide (DMF) solution, which otherwise cannot be electrospun and forms droplets due to inappropriate solution viscosity. The electrospinning was performed under nitrogen because poly[(B-(methylamino)borazine] is sensitive to moisture and air. The as-formed mat was composed of a network of polymer fibers of $500 \mathrm{~nm}$ diameter characterized by smooth cylindrical surface, bead-free, and a reduced diameter distribution. The polymer fibers were first pyrolyzed at $1000{ }^{\circ} \mathrm{C}$ in $\mathrm{NH}_{3}$ atmosphere. The major shrinkage of the fiber was caused by the decomposition of poly[(B(methylamino)borazine] and PAN in ammonia. The FT-IR of the fibers after pyrolyzed at $1000{ }^{\circ} \mathrm{C}$ in $\mathrm{NH}_{3}$ showed incomplete polymer-to-ceramic conversion as indicated by the $\mathrm{C}-\mathrm{N}$ bonds at $1095 \mathrm{~cm}^{-1}$. The subsequent pyrolysis at $1800{ }^{\circ} \mathrm{C}$ under nitrogen is required to generate $\mathrm{BN}$ fibers, which is supported by a strong and broad IR absorption band at $1367 \mathrm{~cm}^{-1}$ and a sharp weak band at $806 \mathrm{~cm}^{-1}$ assigned to $\mathrm{B}-\mathrm{N}$ bonds in the h-BN. ${ }^{53}$ The diameter of the fibers in this process is controlled by tuning the ratio between poly[(B-(methylamino)borazine $]$ and PAN. The fiber diameter decreased from $400 \mathrm{~nm}$ to $100 \mathrm{~nm}$ with reduced ratio.

Producing SiCN fibers through the electrospinning of commercial available preceramic materials, Ceraset $^{\mathrm{TM}}$, is a cost effective fabrication approach. We have developed a unique and simple technique to fabricate $\mathrm{Si}-\mathrm{C}-\mathrm{N}-$ Al ceramic nonwoven mats via the electrospinning of aluminum functionalized oligosilazane. ${ }^{54}$ In our studies, a solid polyaluminasilazane was synthesized by reacting Ceraset $^{\mathrm{TM}}$ with aluminum tri-sec-butoxide. The obtained solid polyaluminasilazane is soluble in common solvents such as chloroform, $N, N$-dimethylformamide (DMF) and acetone. However, polyaluminasilazanes are short polymers with rigid backbones. Electrospinning of all polyaluminasilazane solutions resulted in the formation of polymer droplets due to insufficient chain overlap. In order to improve the spinnability, a small amount ( $0.3 \%$ relative to polyaluminasilazane) of high molecular weight polyethyleneoxide (PEO, MW $=1,000,000)$ was added to the solutions. It is believed that PEO interacts with polyaluminasilazane through hydrogen bonding and offers sufficient chain entanglement for electrospinning. The fiber size and surface structure was controlled by using co-solvents with different ratio of chloroform $\left(T_{\mathrm{b}}=61.2^{\circ} \mathrm{C}\right)$ and the less volatile $\operatorname{DMF}\left(T_{\mathrm{b}}=153.0^{\circ} \mathrm{C}\right)$. Figure 7 shows the effect of chloroform/DMF ratio on the fiber size and morphology of the electrospun polymer fibers. The green fibers are crosslinked by surface hydrolysis. It is seen that fibers obtained from mixture of solvents, chloroform-to-DMF ratio of 0.5 and 1.0, possess dual scale nanostructure domains on their surfaces. The roughness of the fiber surfaces decreases with increase in the chloroform-to-DMF ratio, which is good agreement with the previous studies reporting that the surface roughness is probably caused by the rapid phase separation induced by the differential solvent evaporation rates, and the roughness increases with increase in the boiling point of the mixture of the solvents. ${ }^{55}$ Figure 7 also shows that fiber diameter also decreases with an increase in the DMF content in the solution mixture, which is believed to be due to the increase in the electrical conductivity of the solution (dielectric constants for chloroform and DMF are 4.8 and 36.7 respectively). ${ }^{56}$ The obtained 


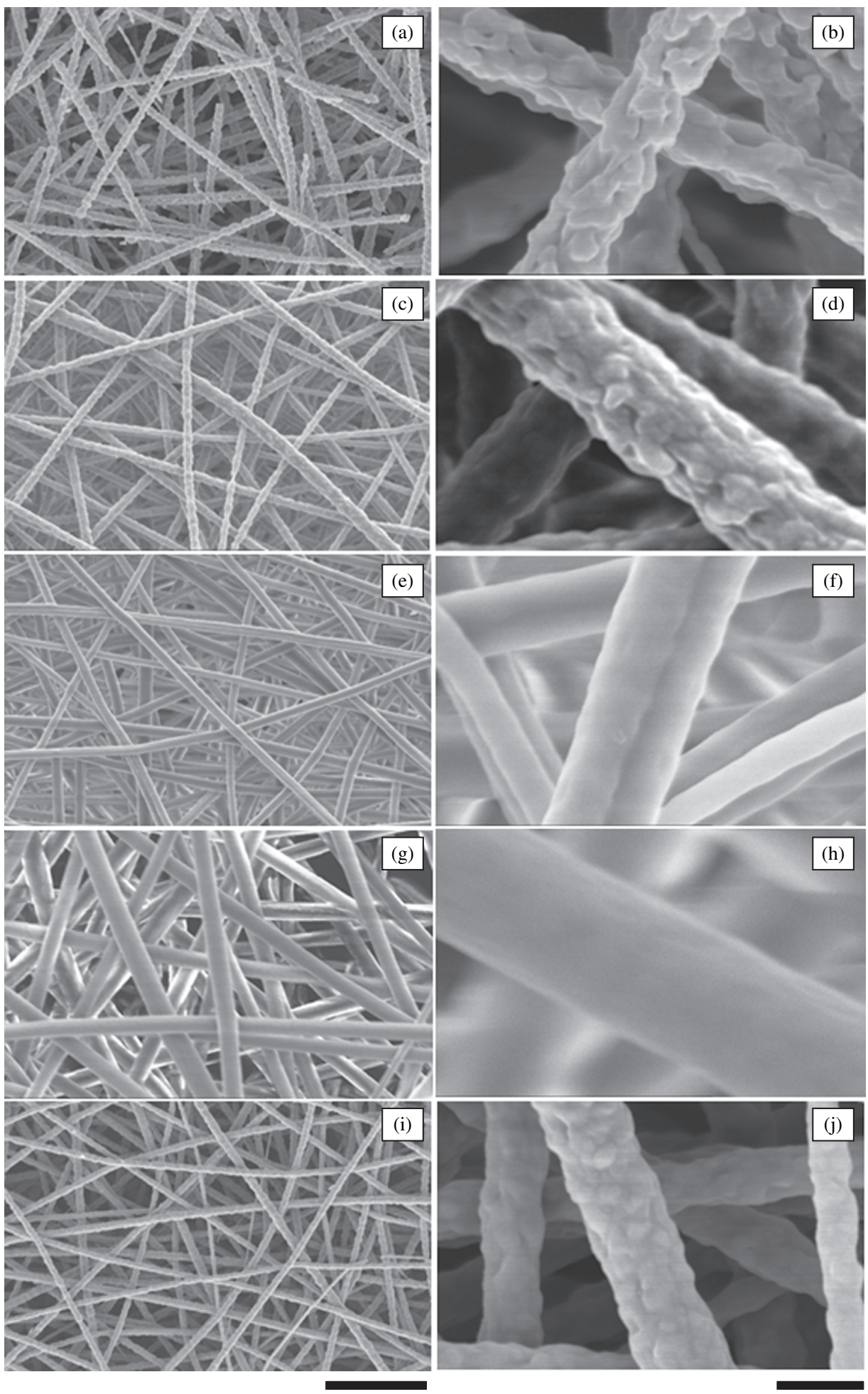

Fig. 7. SEM images of electrospun polysilazane fibers from mixtures of chloroform and DMF ratios (a, b at 1:2; c, d at 1:1; e, f at 2:1; g, h at 5:1). i, $\mathrm{j}$ are the SEM images of c, d after pyrolysis respectively. The scale bar for a, c, e, f. g, i is $10 \mu \mathrm{m}$, and the scale bar of b, d, f, h, j is $1 \mu \mathrm{m}$. Reprinted with permission from [54], S. Sarkar et al., J. Am. Ceram. Soc. 91, 2751 (2008). () 2008, John Wiley \& Sons, Inc.

unwoven polymer mats were then pyrolyzed at $1000{ }^{\circ} \mathrm{C}$ in Ar to convert them into $\mathrm{Si}-\mathrm{C}-\mathrm{N}-\mathrm{Al}$ ceramic fiber mats. As shown in Figures $7(\mathrm{i}, \mathrm{j})$ the surface structure of the preceramic fibers was maintained during the pyrolysis process even though $\sim 28 \%$ linear shrinkage occur during the pyrolysis. These dual scale length surface structures provided a suitable template for superhydrophobic surfaces. These ceramic fibers with nanostructured surfaces became 
superhydrophobic after successful chemical vapor deposition (CVD) of low surface energy material, trichloro $(1 \mathrm{H}$, $1 \mathrm{H}, 2 \mathrm{H}, 2 \mathrm{H}$-perfluorooctyl) silane. These ceramic nanostructures remain intact even after thermal treatment at $450{ }^{\circ} \mathrm{C}$, and the lost superhydrophobicity could be further rebuilt via further deposition of perfluorosilane. Such thermal stability makes these ceramic fiber mats applicable for removing various surface contaminations. Also these ceramic superhydrophobic surfaces showed excellent resistant to potentially harmful organic solvents, strong acids and bases; consequently making them potentially applicable in military's toxicological agent protective suites.

Since direct polymer-to-ceramic process allows the incorporation of functional materials including polymer fillers and carbons to ceramics, we rationalized that ceramic fiber with aligned carbon nanotubes (CNTs) could be fabricated by pyrolyzing CNT/preceramic polymer electrospun fibers produced from preceramic polymer solutions with CNTs dispersed by conjugated block copolymers. Accordingly, we reported the fabrication of ceramic fibers with aligned CNTs from preceramic polymer solutions containing dispersed multiwall carbon nanotubes (MWCNTs) ${ }^{57}$ MWCNTs were dispersed by conjugated block copolymer, poly(3hexylthiophene)- $b$-poly(poly(ethylene glycol) methyl ether acrylate) (P3HT- $b$-PPEGA) in chloroform solutions of polyaluminasilazane, a synthesized solution processable preceramic polymer. PPEGA groups on P3HT- $b$-PPEGA functionalized CNTs are compatible with polyaluminasilazane through hydrogen bonding and generate a stable dispersion of MWCNT in polyaluminasilazane solutions. Electrospinning of the MWCNT/polyaluminasilazane solutions produced polyaluminasilazane fibers with well aligned CNTs. Subsequently, the electrospun fibers were pyrolyzed to obtain SiAlCN ceramic fibers with aligned MWCNTs. Figure 8 shows the SEM images of MWCNT/polyaluminasilazane electrospun fibers from the composite solutions of polyaluminasilazane and MWCNT at different concentrations. The fiber diameter decreases from about $4 \mu \mathrm{m}$ to $1 \mu \mathrm{m}$ as the polyaluminasilazane concentration decreases from $20 \%$ to $5 \%$ and the MWCNT concentration increases from $0.2 \%$ to $1.2 \%$. The roughening of the fibers at high CNT concentration is due to the increased electric field caused by the high electrical conductivity of CNT in the polymer solution. The electrospun fibers were pyrolyzed at $1000{ }^{\circ} \mathrm{C}$ for 1 hour under Ar atmosphere. As shown in Figures $8(\mathrm{i}, \mathrm{j})$ the fiber structure and the aligned CNTs remain unchanged during the pyrolysis. SiAlCN ceramic fibers with $1.2 \%$ MWCNTs showed electrical conductivity 500 times higher that of the SiAlCN bulk ceramics, demonstrating the large improvement of the electrical conductivity attributed to the aligned CNTs. Our reported method provides a simple, versatile and non-invasive approach to disperse CNT in PDCs and paves a new path to align CNTs in ceramic fibers. Although the mechanical properties of these composite fibers are current under investigation, MWCNTs were added to polycarbosilazane in other studies to produce MWCNTs reinforced ceramic fibers. Small amount of MWCNTs greatly improved the mechanical properties and spinnability of green fibers. ${ }^{58}$ These ceramic fibers could find potential applications in CMCs with excellent electrical and mechanical properties.

Blending preceramic polymers with other commonly used polymers followed by electrospinning can generate nanostructures in polymer fibers through the phase separation between two types of polymer. This approach allows the fabrication of ceramic fibers with nanosize structures that can be using in the applications where large surface area is desired. Polyureasilazane (PUS), a lowviscous thermoset PDC precursor, has been blended with poly(methylmethacrylate) (PMMA) ${ }^{59}$ and polyacrylonitrile $(\mathrm{PAN})^{60}$ to fabricate green fibers that generate silicon oxycarbide fibers. Different ceramic fiber composition and structures were created from PUS/PMMA and PUS/PAN blends. The phase separation between PUS and PMMA caused the formation of PUS nanoparticles in PMMA matrix. These nanoparticles were crosslinked by a peroxide catalyst. The green fibers were pyrolyzed under nitrogen atmosphere at $500{ }^{\circ} \mathrm{C}$ and converted to $\mathrm{SiCO}$ ceramic fibers (Fig. 9(a)). After pyrolysis, PMMA almost decomposed completely while the cross-linked PUS polymer lost $19.7 \mathrm{wt} \%$ from the escape of volatile ammonia, hydrogen, and hydrocarbons (such as methane) during pyrolysis. The fibers have a patterned shell structure filled with nanoparticles when examined by SEM (Figs. 9(b and c)). The TEM studies on cross sections of sliced fibers also showed the encapsulated nanoparticles with an average diameter of $50 \mathrm{~nm}$ (Fig. 9(d)). The authors believed that the formation of a luffa-like "skin" of the fiber was caused by larger volume shrinkage in the fiber core resulted from the PMMA decomposition compared with that on the fiber surface. The loose "skin" on the surface had to be wrinkled to follow the contracted core volume, leading to an appearance of longitudinal striations.

Similarly, polymer-derived silicon oxycarbide ( $\mathrm{SiCO})$ ceramic doped carbon fibers with an average diameter of $165 \mathrm{~nm}$ were successfully fabricated by simple electrospinning of the mixtures of PUS and PAN, a commonly available carbon fiber precursor polymer, followed by oxidative stabilization and pyrolysis at $1000{ }^{\circ} \mathrm{C}$ in air and Ar, respectively. ${ }^{60}$ The resultant fiber structure, morphology and properties were thoroughly investigated. PUS was chosen as the PDC precursor because of its low viscosity allowing mixing with PAN at $5 / 7 \mathrm{w} / \mathrm{w}$ PUS/PAN ratio to achieve a $12 \mathrm{wt} \%$ total polymer concentration without any phase separation. SiCO doped carbon fibers showed enhanced thermal stability and tensile properties, such as elongation at break, and most significantly, improved flexibility that was demonstrated by full recovery 

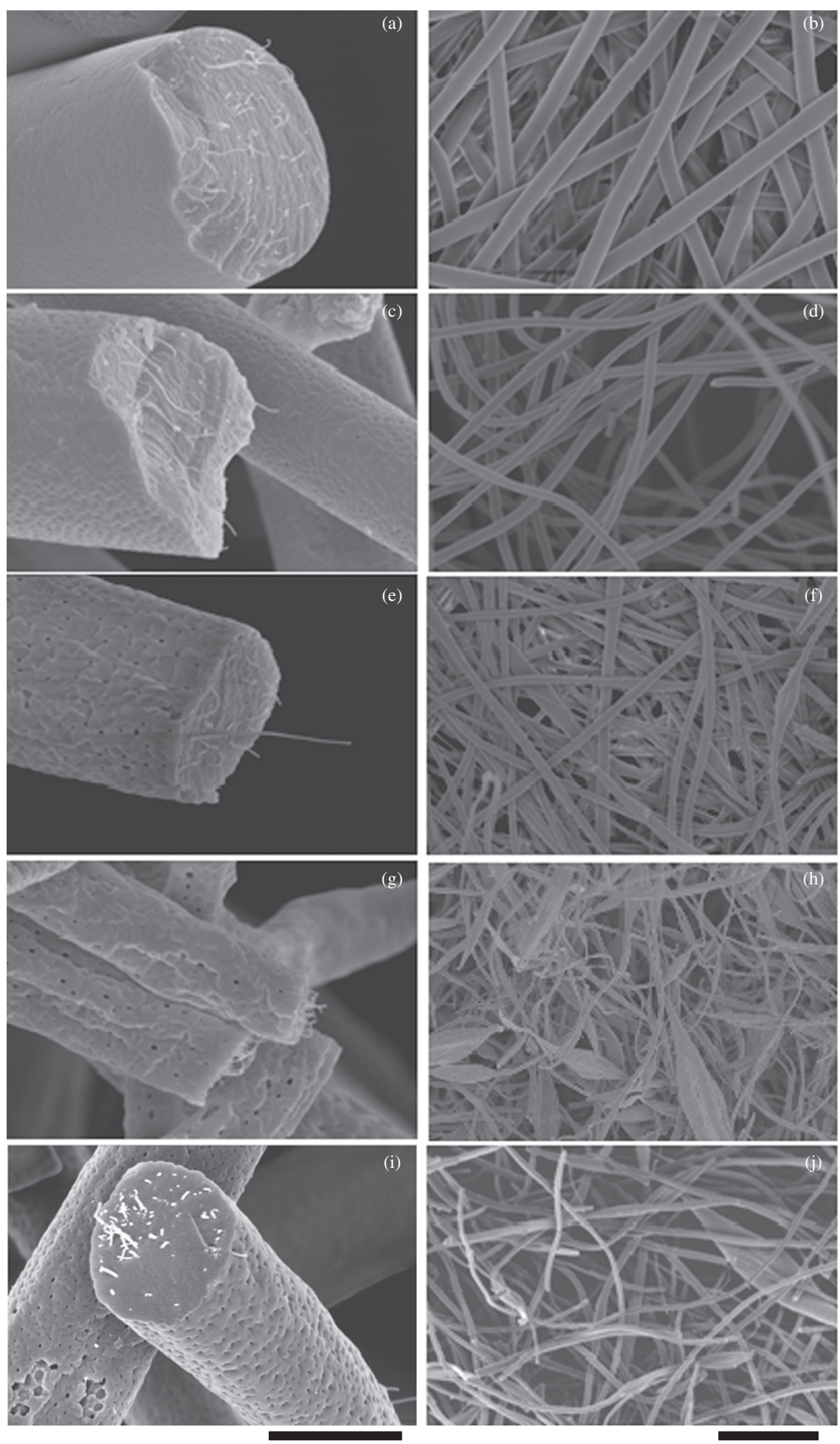

Fig. 8. SEM images of electrospun fibers from different compositions of polyaluminasilazane and MWCNT: (a, b) 20\% polyaluminasilazane/0.2\% MWCNT; (c, d) 15\% polyaluminasilazane/0.3\% MWCNT; (e, f) $10 \%$ polyaluminasilazane/0.5\% MWCNT; (g, h) 5\% polyaluminasilazane/1.2\% MWCNT. $\mathrm{i}, \mathrm{j}$ are the SEM images of $\mathrm{g}, \mathrm{h}$ after pyrolysis respectively. The scale bar for a, c, e, g, and i is $2 \mu \mathrm{m}$ and for $\mathrm{b}, \mathrm{d}, \mathrm{f}, \mathrm{h}$, and $\mathrm{j}$ is $10 \mu \mathrm{m}$. Reprinted with permission from [57], S. Sarkar et al., ACS Applied Materials \& Interfaces 2, 1150 (2010). () 2010, American Chemical Society.

without any fracture. The $\mathrm{SiCO} /$ carbon fibers also demonstrated dual superhydrophiliciy and superoleophilicity with $873 \%$ water absorption and $608 \%$ decane absorption capacities. In addition, $\mathrm{SiCO} /$ carbon fibers possessed better capacitor properties than the carbon fibers. In summary, this research opens a window of opportunity to fabricate multicomponent ceramic domains and structures from preceramic polymer/polymer blends with unique physical, 

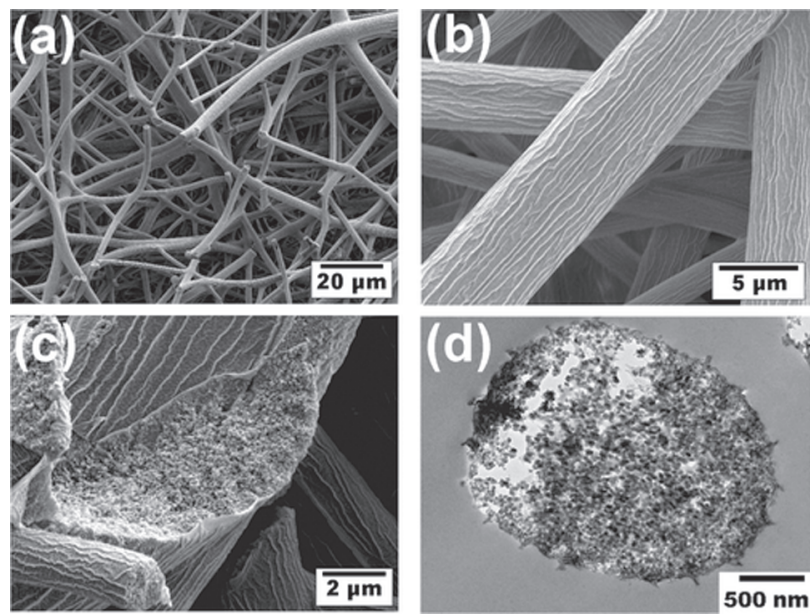

Fig. 9. SEM images of (a) as-calcined fibers, (b) their luffa-like surface pattern, and (c) a cross section showing compacted nanoparticles. (d) TEM image of a thin section also reveals capsulated nanoparticles forming a macroporous fiber. Reprinted with permission from [59], P. Lu et al., J. Am. Chem. Soc. 131, 10346 (2009). (C) 2009, American Chemical Society.

mechanical, and electrical properties that could potentially make them good candidates for high temperature applications, such as sensors, catalyst support materials, protective coating, flexible electronics, etc.

Electrospinning of preceramic polymers offers a versatile and controllable approach to produce nanosize ceramic fibers that can not be achieved by other methods. The integration of other functional materials into the polymer fibers introduces additional functionality and structure to the ceramic fibers, opening a gate to new applications. On the other hand, due to the small fiber size, the characterization of the mechanical properties of the fibers requires unconventional technique such as using atomic force microscope (AFM). ${ }^{61}$ The alignment of ceramic fibers can be achieved during the electrospinning process using different collection electrodes. ${ }^{8}$

\section{CONCLUSION AND OUTLOOK}

Fabricating ceramic fibers from precursor polymers provides incomparable opportunity to create both binary and multicomponent phase non-oxide ceramic fibers. By controlling the composition and physical properties of polymer precursors, green polymer fibers with size ranging from nanometers to microns have been fabricated by electrospinning and melt-spinning. The thermal stability and oxidation resistance of the pyrolyzed ceramic fibers is determined by the composition of the polymer precursors and curing conditions. Such polymer-derived ceramic fibers have emerged as important materials in a variety of applications such as CMCs, which is illustrated by commercialized $\mathrm{SiC}$ based ceramic fibers $\left(\mathrm{Nicalon}^{\mathrm{TM}}\right)$. With the increasing demand of high performance materials in aerospace and power generating industry, ceramic fibers that can withstand $1500{ }^{\circ} \mathrm{C}$ in oxidizing/corrosive environment are highly desirable. SiBCN ceramic fibers have demonstrated outstanding thermal stability and oxidation resistance at such high temperature, suggesting that multicomponent ceramic fibers are promising candidates for aerospace and power generating industry. Furthermore, the polymer-to-ceramic process allows the incorporation of other interesting properties to final ceramic fibers. For example, ferrocene was added to polydimethylsilane to introduce $\mathrm{Fe}$ content in $\mathrm{Si}-\mathrm{C}-\mathrm{O}$ ceramic fibers. The resultant $\mathrm{Si}-\mathrm{Fe}-\mathrm{C}-\mathrm{O}$ ceramic fibers demonstrated magnetic properties and reduced specific resistance. ${ }^{62}$ These studies demonstrated that material development holds the key to the success of fabricating non-oxide ceramic fibers through cost effective methods. In addition, while the chemical composition evolution of PDCs has been extensively investigated using a variety of characterization methods such as solid state nuclear magnetic resonance (NMR) and electron paramagnetic resonance (EPR), more investigation of mechanical properties of ceramic fibers, especially those produced through the electrospinning process is required to realize their applications in aircraft engine parts, gas turbine components, heat exchangers and many other fields.

Although achieving strong ceramic fibers with extraordinary thermal stability was the original motivation to study PDC ceramic fibers, Si-based PDCs have demonstrated a variety of interesting properties including the semiconductivity properties ${ }^{63,64}$ and the piezoresistivity ${ }^{65} \mathrm{SiCO}$ and $\mathrm{SiCN}$ ceramic with graphite have shown interesting electrochemical properties with potential applications as anode material in Li-ion batteries. ${ }^{66}$ In the application of energy storage devices, large surface area of the electrodes enable the efficient usage of active materials and accessibility of electrolytes or $\mathrm{Li}$ ions. Therefore, the nanosize ceramic fibers fabricated through the electrospinning have great potential in such applications. Ceramic fibrous electrode materials are promising candidates in high power and mobile energy applications such as electric and hybrid electric vehicles. The application of nanosize PDC fibers can extend to catalyst supports and filters for liquid and (hot) gas separation processes. The fabrication of PDC fibers with controlled nanosize structures and more functionalities will be the goal of the future research. Current research in incorporating nanomaterials including carbon nanotubes, graphene and nanoparticles with PDC fibers and using polymer blends to produce fibers with nanostructures will require detailed characterization of the fiber composition and structures. The combination of well-designed chemical synthesis, materials processing and characterization will offer numerous opportunities for new classes of polymer-derived ceramic fibers.

Acknowledgments: The authors gratefully acknowledge National Science Foundation (DMR0706526) for financial support. 


\section{References and Notes}

1. W. Krenkel, R. Naslain, and H. Schneider (eds.), High Temperature Ceramic Matrix Composites, John Wiley \& Sons Inc., New York (2006).

2. F. W. Ainger and J. M. Herbert, The Preparation of PhosphorousNitrogen Compounds as Nonporous Solids in Special Ceramics, edited by P. Popper, Academic Press, New York (1960).

3. P. G. Chantrell and P. Popper, Inorganic Polymers for Ceramics in Special Ceramics, edited by P. Popper, Academic Press, New York (1965).

4. A. L. Yarin, S. Koombhongse, and D. H. Reneker, J. Appl. Phys. 89, 3018 (2001).

5. Y. M. Shin, M. M. Hohman, M. P. Brenner, and G. C. Rutledge, Appl. Phys. Lett. 78, 1149 (2001).

6. Y. M. Shin, M. M. Hohman, M. P. Brenner, and G. C. Rutledge, Polymer 42, 9955 (2001).

7. D. Li and Y. Xia, Adv. Mater. 16, 1151 (2004).

8. D. Li, Y. Wang, and Y. Xia, Adv. Mater. 16, 363 (2004).

9. T. Subbiah, G. S. Bhat, R. W. Rock, S. Parameswaran, and S. S. Ramkumar, J. Appl. Polym. Sci. 96, 557 (2005).

10. E. Fitzer and M. Heine, Fiber Reinforcements for Composite Materials, edited by A. R. Bunsell, Elsevier, New York (1988), pp. 79-148.

11. S. Yajima, Y. Hagesawa, K. Okamura, and T. Matsuzawa, Nature 273, 525 (1978).

12. Y. Hagesawa, M. Iimura, and S. Yajima, J. Mater. Sci. 15,720 (1980).

13. H. Ichikawa, F. Machino, S. Mitsuno, T. Ishikawa, K. Okamura, and Y. Hagesawa, J. Mater. Sci. 21, 4352 (1986).

14. T. Taki, S. Maeda, K. Okamura, M. Sato, and T. Matsuzawa, J. Mater. Sci. Lett. 6, 826 (1987).

15. T. Taki, K. Okamura, M. Sato, T. Seguchi, and S. Kawanishi, J. Mater. Sci. Lett. 7, 1013 (1988).

16. M. Sugimoto, T. Shimoo, K. Okamura, and T. Seguchi, J. Am. Ceram. Soc. 78, 1013 (1996).

17. M. Takeda, J. Sakamoto, Y. Imai, and H. Ichikawa, Compos. Sci. Technol. 59, 813 (1999).

18. S. M. Johnson, R. D. Brittain, R. H. Lamoreaux, and D. J. Rowcliffe, J. Am. Ceram. Soc. 71, C-132 (1988).

19. T. Mah, N. L. Hectht, D. E. McCullum, J. R. Hoenigman, H. M. Kim, A. P. Katz, and H. A. Lipsitt, J. Mater. Sci. 19, 1191 (1984).

20. S. Yajima, T. Iwai, T. Yamamura, K. Okamura, and Y. Hasegawa, J. Mater. Sci. 16, 1349 (1981).

21. T. Yamamura, T. Ishikawa, M. Shibuya, and K. Okamura, J. Mater. Sci. 23, 2589 (1988).

22. K. Okamura, Adv. Composite Mater. 8,107 (1999).

23. G. Motz, J. Hacker, G. Ziegler, B. Clauss and D. Schawaller, Advanced Inorganic Structural Fiber Composites, edited by P. Vincenzini and C. Badini, Techna Srl, Faenza (2004), Vol. 4, p. 47.

24. A. Saha, S. R. Shah, and R. Raj, J. Am. Ceram. Soc. 86, 1443 (2003).

25. D. Mocaer, G. Chollon, R. Pailler, L. Filipuzzi, and R. Naslain, J. Mater. Sci. 28, 3059 (1993).

26. G. Chollon, M. Czernaik, R. Pailler, X. Bouratt, R. Naslain, J. P. Pillot, and R. Cannet, J. Mater. Sci. 32, 893 (1997).

27. G. Chollon, R. Pailler, R. Naslain, F. Lannani, M. Monthioux, and P. Olry, J. Mater. Sci. 32, 327 (1997).

28. G. Chollon, J. Eur. Ceram. Soc. 20, 1959 (2000).

29. A. Saha, S. R. Shah, and R. Raj, J. Am. Ceram. Soc. 87, 1556 (2004).

30. T. Ishikawa, Y. Kohtoku, K. Jumagawa, T. Yamamura, and T. Nagasawa, Nature 391, 773 (1998).

31. R. Riedel, A. Kienzle, W. Dressler, L. Ruwlsch, J. Bill, and F. Aldinger, Nature 382, 796 (1996).

32. M. Jansen, B. Jäschke, and T. Jäschke, Struct. Bonding 101, 137 $\underline{\text { (2002). }}$.
33. T. Wideman, E. Cortez, E. E. Remsen, G. A. Zank, P. J. Carrol, and L. G. Sneddon, Chem. Mater. 5, 547 (1993).

34. W. R. Schmidt, D. M. Narsavage-Heald, D. Jones, M. P. S. Marchetti, D. Raker, and G. E. Maciel, Chem. Mater. 11, 1455 (1999).

35. J. Haberecht, R. Nesper, and H. Grütmacher, Chem. Mater. 17, 2340 (2005).

36. M. Weinmann, M. Hörz, F. Berger, A. Müller, K. Müller, and F. Aldinger, J. Organomet Chem. 659, 29 (2002).

37. T. Jäschke and M. Jansen, J. Mater. Chem. 26, 2792 (2006).

38. T. Jäschke and M. Jansen, J. Eur. Ceram. Soc. 25, 211 (2005).

39. S. Bernard, M. Weinmann, P. Gerstel, P. Miele, and F. Aldinger, J. Mater. Chem. 15, 289 (2005).

40. J. Lee, D. P. Butt, R. H. Baney, C. R. Bowers, and J. S. Tulenko, J. Non-Cryst. Solids 351, 2995 (2005).

41. Z.-C. Wang, F. Aldinger, and R. Riedel, J. Am. Ceram. Soc. 84, 2179 (2001).

42. M. A. Schiavon, G. D. Sorarù, and I. V. P. Yoshida, J. Non-Cryst. Solids 348, 156 (2004).

43. M. Cinibulk and T. A. Parthasarathy, J. Am. Ceram. Soc. 84, 2197 (2001).

44. T. Wideman, E. Cortez, E. E. Remsen, G. A. Zank, R. J. Carrol, and L. G. Sneddon, Chem. Mater. 9, 2218 (1997).

45. S. Bernard, M. Weinemann, P. Gerstel, P. Miele, and F. Aldinger, J. Chem. Mater. 15, 289 (2005).

46. P. Baldus, M. Jansen, and D. Sporn, Science 285, 699 (1999)

47. Y. Tang, J. Wang, X.-D. Li, H. Wang, W.-H. Li, and X.-Z. Wang, J. Appl. Polym. Sci. 110, 921 (2008).

48. S. L. Shenoy, W. D. Bates, H. L. Frisch, and G. E. Wnek, Polymer 46, 3372 (2005).

49. J. H. Yu, S. V. Fridrikh, and G. C. Rutledge, Polymer 47, 4789 (2006).

50. D. T. Welna, J. D. Bender, X. Wei, L. G. Sneddon, and H. R. Allcock, Adv. Mater. 17, 859 (2005).

51. B. M. Eick and J. P. Youngblood, J. Mater. Sci. 44, 160 (2009).

52. V. Salles, S. Bernard, A. Brioude, D. Cornu, and P. Miele, Nanosize 2, 215 (2010)

53. R. J. Nemanich, S. A. Solin, and R. M. Martin, Phys. Rev. B: Condens. Matter 23, 6348 (1981).

54. S. Sarkar, A. Chunder. W. Fei, L. An, and L. Zhai, J. Am. Ceram. Soc. 91,2751 (2008).

55. S. Megelski, J. S. Stephens, D. B. Chase, and J. F. Rabolt, Macromolecules 35, 8456 (2002).

56. C.-M. Hsu and S. Shivkumar, Macromol. Mater. Eng. 289, 334 (2004).

57. S. Sarkar, J. Zou, J. Liu, C. Xu, L. An, and L. Zhai, ACS Applied Materials \& Interfaces 2, 1150 (2010).

58. S. Kokott, L. Heymann, and G. Motz, J. Eur. Ceram. Soc. 28, 1015 (2008).

59. P. Lu, Q. Huang, B. Liu. Y. Bando, Y.-L. Hsieh, and A. K. Mukherjee, J. Am. Chem. Soc. 131, 10346 (2009).

60. P. Lu, Q. Huang, A. Mukherjee, and Y.-L. Hsieh, ACS Applied Materials \& Interfaces 2, 3738 (2010).

61. M.-F. Yu, B. S. Files, S. Arepalli, and R. S. Ruoff, Phys. Rev. Lett. 24, 5552 (2000).

62. Z.-Y. Chen, X.-D. Li, W. Jun, and W.-F. Li, Trans. Nonferrous Met Soc. China 17, 987 (2007).

63. J. Cordelair and P. Greil, J. Eur. Ceram. Soc. 20, 1947 (2000).

64. C. Haluschka, C. Engel, and R. Riedel, J. Eur. Ceram. Soc. 20, 1365 (2000).

65. L. Zhang, Y. Wang, Y. Wei, W. Xu, D. Fang, L. Zhai, K.-C. Lin, and L. An, J. Am. Ceram. Soc. 91, 1346 (2008).

66. R. Kolb, C. Fasel, V. Liebau-Kunzmann, and R. Riedel, J. Eur. Ceram. Soc. 26, 3903 (2006).

Received: 16 January 2011. Revised/Accepted: 23 February 2011. 